\title{
Pemodelan Perambatan Gelombang Tsunami di Perairan Teluk Palu dengan Metode Transformasi Koordinat Bola
}

\author{
Gusni $^{1}$, A.I. Jaya ${ }^{2}$ dan R. Ratianingsih ${ }^{3}$ \\ 1,2,3Jurusan Matematika FMIPA Universitas Tadulako, \\ Jalan sukarno-Hatta Palu, \\ 19husny_Palu@yahoo.com, 3ratianingsih@yahoo.com
}

\section{Abstrak}

Salah satu bencana alam yang pernah terjadi akibat gempa tektonik di kota Palu adalah Tsunami. Pengamatan perambatan Gelombang Tsunami ini menjadi prioritas karena dapat mengakibatkan kerusakan wilayah dan menelan korban. Untuk dapat mengetahui perambatan gelombang Tsunami di Kota Palu maka dilakukan pemodelan terhadap perambatan glombang tsunami di perairan teluk palu. Model tersebut dibangun oleh sistem persamaan diferensial parsial. Solusi persamaan pembangun model ditentukan secara analitik dengan metode transformasi koordinat bola. Hasil yang diperoleh yaitu model persamaan gelombang tsunami tiga dimensi dengan metode transformasi koordinat bola adalah sebagai berikut:

$$
\begin{aligned}
\bar{M}\left(A,\left(\vartheta_{1}, \vartheta_{2}\right), t\right)=( & \left.\frac{1}{\mathrm{~g}} \frac{\mathrm{J}}{5}\right) \frac{\partial^{2} M}{\partial t^{2}}+\left[\frac{6}{A^{2}} \frac{\partial}{\partial A}\left(A^{2} \frac{\partial}{\partial A}\right)\right]+\frac{4}{A^{2} \sin ^{2} \vartheta_{2}} \frac{\partial}{\partial \vartheta_{1}}\left(\sin ^{2} \vartheta_{2} \frac{\partial}{\partial \vartheta_{1}}\right)+\left[\frac{4}{A^{2} \sin ^{2} \vartheta_{2}} \frac{\partial^{2}}{\partial \vartheta_{2}^{2}}-\frac{1}{A^{2} \sin ^{2} \vartheta_{2}} \frac{\partial^{2}}{\partial \vartheta_{2}}\right] \\
& +\frac{4}{A^{2} \cos ^{2} \vartheta_{1}} \frac{\partial}{\partial \vartheta_{2}}\left(\cos ^{2} \vartheta_{1} \frac{\partial}{\partial \vartheta_{2}}\right)+\left[\frac{4}{A^{2} \cos ^{2} \vartheta_{1}} \frac{\partial^{2}}{\partial \vartheta_{1}^{2}}-\frac{1}{A^{2} \cos \vartheta_{1}} \frac{\partial}{\partial \vartheta_{1}}\left(\cos \vartheta_{1} \frac{\partial}{\partial \vartheta_{1}}\right)\right]=0
\end{aligned}
$$

Dan Solusi fungi perambatan gelombang tsunami adalah sebagai berikut :

$\bar{M}(U, V, t)=\left((E) e^{-(\chi) x^{2}-(\omega) y^{2}+\left(\frac{1 J^{2}}{\mathrm{~g} 5}\right)(\gamma) t^{2}}\right)+$

$e^{\mathrm{Y}_{1} t\left(2 C_{2} \cos \frac{1}{2}\left[\frac{1}{5} \sqrt{10 J \psi} t+\left(\frac{\eta_{i-1, j+1}^{t}}{L_{X}}\right) u\right] \cdot C_{2} \sin \frac{1}{2}\left[\frac{1}{5} \sqrt{10 J \psi} t-\left(\frac{\eta_{i-1, j+1}^{t}}{L_{X}}\right) u\right]-2 C_{1} \sin \frac{1}{2}\left[\frac{1}{5} \sqrt{10 J \psi} t+\left(\frac{\eta_{i+1, j-1}^{t}}{L_{y}}\right) v\right] \cdot C_{1} \sin \frac{1}{2}\left[\frac{1}{5} \sqrt{10 J \psi} t-\left(\frac{\eta_{i+1, j-1}^{t}}{L_{y}}\right) v\right]\right)^{2}}$

Dimana simulasi model memperlihatkan waktu perambatan gelombang tsunami di perairan teluk palu mencapai daratan pada saat 705 detik atau 11,75 menit dengan kecepatan yang sejajar laut $45 \mathrm{~km} / \mathrm{menit}$ dan mengarah ke darat $68 \mathrm{~km} / \mathrm{menit}$.

Kata Kunci : Gelombang Tsunami, Transformasi koordinat Bola, Metode Pemisahan Variabel,Persamaan Differensial Parsial 


\section{Abstract}

One of the natural disaster which have happened effect of earthquake of tektonik in Hammer town is Tsunami. Perception of wave propagation of this Tsunami become priority because can result damage of region and swallow victim. To be able to know wave propagation of Tsunami in Town Hammer hence pemodelan to wave velocity territorial water of hammer bay. The model woke up by sistem equation of parsial diferensial. Solution equation of constructor of model determined analyticly with method of transformasi ball co-ordinate. Result of which is obtained that is model wave equation of tsunami three dimension with method of transformasi ball coordinate shall be as follows:

$$
\begin{aligned}
\bar{M}\left(A,\left(\vartheta_{1}, \vartheta_{2}\right), t\right)=( & \left.\frac{1}{\mathrm{~g}} \frac{J}{5}\right) \frac{\partial^{2} M}{\partial t^{2}}+\left[\frac{6}{A^{2}} \frac{\partial}{\partial A}\left(A^{2} \frac{\partial}{\partial A}\right)\right]+\frac{4}{A^{2} \sin ^{2} \vartheta_{2}} \frac{\partial}{\partial \vartheta_{1}}\left(\sin ^{2} \vartheta_{2} \frac{\partial}{\partial \vartheta_{1}}\right)+\left[\frac{4}{A^{2} \sin ^{2} \vartheta_{2}} \frac{\partial^{2}}{\partial \vartheta_{2}^{2}}-\frac{1}{A^{2} \sin ^{2} \vartheta_{2}} \frac{\partial^{2}}{\partial \vartheta_{2}}\right] \\
& +\frac{4}{A^{2} \cos ^{2} \vartheta_{1}} \frac{\partial}{\partial \vartheta_{2}}\left(\cos ^{2} \vartheta_{1} \frac{\partial}{\partial \vartheta_{2}}\right)+\left[\frac{4}{A^{2} \cos ^{2} \vartheta_{1}} \frac{\partial^{2}}{\partial \vartheta_{1}{ }^{2}}-\frac{1}{A^{2} \cos \vartheta_{1}} \frac{\partial}{\partial \vartheta_{1}}\left(\cos \vartheta_{1} \frac{\partial}{\partial \vartheta_{1}}\right)\right]=0
\end{aligned}
$$

And Solution of fungi wave propagation of tsunami shall be as follows :

$\bar{M}(U, V, t)=\left((E) e^{-(\chi) x^{2}-(\omega) y^{2}+\left(\frac{1 J^{2}}{\mathrm{~g} 5}\right)(\gamma) t^{2}}\right)+$

$e^{\mathrm{Y}_{1} t\left(2 C_{2} \cos \frac{1}{2}\left[\frac{1}{5} \sqrt{10 J \psi} t+\left(\frac{\eta_{i-1, j+1}^{t}}{L_{X}}\right) u\right] \cdot C_{2} \sin \frac{1}{2}\left[\frac{1}{5} \sqrt{10 J \psi} t-\left(\frac{\eta_{i-1, j+1}^{t}}{L_{X}}\right) u\right]-2 C_{1} \sin \frac{1}{2}\left[\frac{1}{5} \sqrt{10 J \psi} t+\left(\frac{\eta_{i+1, j-1}^{t}}{L_{y}}\right) v\right] \cdot C_{1} \sin \frac{1}{2}\left[\frac{1}{5} \sqrt{10 J \psi} t-\left(\frac{\eta_{i+1, j-1}^{t}}{L_{y}}\right) v\right]\right)^{2}}$

Where model simulation show time wave propagation of tsunami in territorial water of tired hammer bay of continent at the time of 705 second or 11,75 minute with parallel speed sea $45 \mathrm{~km}$ or flange and minute to land $68 \mathrm{~km} /$ minute.

Keyword

\section{: Waving Tsunami, Transformasi Co-Ordinate Ball, Method Dissociation Of Variabel,Persamaan} Differensial Parsial.

\section{Pendahuluan}

Ibu kota Sulawesi Tengah yaitu kota Palu merupakan salah satu Daerah yang memiliki tingkat kegempaan yang cukup tinggi di Indonesia. Hal ini dikarenakan lokasi kota Palu berada pada zona benturan tiga lempeng tektonik utama dunia, yaitu Indo-Australia, Eurasia dan Pasifik. Pertemuan ketiga lempeng ini bersifat konvergen dan ketiganya bertumbukan secara relatif.

Klaster seismisitas gempa bumi dangkal ini terkonsetrasi hampir merata baik di lepas pantai maupun di daratan dan memberikan gambaran bahwa di kawasan ini kondisi tektoniknya sangat aktif. Apalagi kondisi seismisitas dan tektonik yang ada mendukung untuk terjadinya gempa bumi kuat dengan kedalaman dangkal yang dapat membangkitkan tsunami. Kondisi seismisitas ini menujukkan bahwa daerah Palu dan sekitarnya merupakan daerah yang rawan terhadap gempa bumi dan tsunami.

Berdasarkan kondisi tesebut, kajian mengenai potensi bahaya tsunami sangat penting untuk dilakukan. Pengungkapan bahaya tersebut dapat digambarkan melalui pengamatan terhadap profil perambatan gelombang tsunami. Dalam penelitian ini perambatan gelombang tersebut dikaji secara matematis melalui solusi model matematika yang merepresentasikannya. Model tersebut dibangun 
oleh sistem persamaan diferensial parsial. Solusi persamaan pembangun model ditentukan secara analitik dengan metode transformasi koordinat. Melalui metode tersebut perambatan gelombang tsunami di setiap waktu pada suatu posisi tertentu diamati secara iteratif. Pengamatan tersebut dilakukan terhadap perubahan percepatan dan waktu yang diperlukan oleh Gelombang Tsunami untuk mencapai darat atau pinggir pantai.

Hasil penelitian ini diharapkan dapat memberikan informasi bagi perencanaan dan pengembangan kawasan pantai di wilayah Kota Palu dan sekitarnya. Selain itu untuk meningkatkan kesadaran dan kewaspadaan masyarakat terhadap bahaya tsunami yang dapat terjadi setiap saat. Hasil tersebut di harapkan akan memperkecil dampak (mitigasi) suatu bencana.

\section{Metode Penelitian}

Metode yang digunakan dalam penelitian ini adalah sebagai berikut:

a. Memulai penelitian.

b. Melakukan tinjauan pustaka tentang Teori Perairan Dangkal, Teori Tsunami dan metode transformasi Koordinat Bola

c. Merumuskan masalah.

d. Menentukan Model Perambatan Gelombang Tsunami.

e. Melakukan Transformasi Koordinat Kartesian ke dalam Koordinat Bola pada Model Perambatan Gelombang Tsunami.

f. Menentukan solusi Perambatan Gelombang Tsunami.

g. Menyimpulkan hasil penelitian.

\section{Tinjauan Pustaka}

\subsection{Teori Lempeng Tektonik}

Teori Lempeng Tektonik merupakan teori yang digunakan untuk mengetahui proses terjadinya tsunami akibat gempa tektonik. Teori ini berawal dari pengamatan Alfred Wagener seorang ahli meteorologi dan geologi dari Jerman dalam buku The Origin of Continents an Oceans (1915) yang mengemukakan bahwa benua yang padat sebenarnya terapung dan bergerak di atas massa yang relatif lembek (continental drift).

Menurut teori lempeng tektonik, kerak bumi terpecah-pecah menjadi beberapa bagian yang kemudian disebut Lempeng (Plate). Terdapat tujuh lempeng besar (Mega Plate), yaitu : Lempeng Eurasia, Lempeng Pasifik, Lempeng Amerika Utara, Lempeng Amerika Selatan, Lempeng IndoAustralia, Lempeng Afrika, dan Lempeng Antartika. Lempeng-lempeng tersebut bergerak dengan 
arah dan kecepatan yang berbeda antara lempeng satu dengan lempeng yang lainnya. Pergerakan lempeng-lempeng tersebut disebabkan oleh adanya arus konveksi di dalam mantel bumi.

Berdasarkan gaya penyebabnya, sesar dapat dibagi menjadi :

a. Reverse fault atau Trust fault (sesar naik) yaitu sesar dimana hangin wall pada sesar bergerak relatif naik terhadap footwall.

b. Normal fault (sesar turun) yaitu sesar dimana hanging wall pada sesar relative turun terhadap foot wall.

c. Stike slip fault (sesar mendatar) yaitu sesar dengan arah gerakan relatif mendatar satu sama lainya.

\subsection{Kondisi Tektonik dan Geologi Kota Palu}

Ibukota Propinsi Sulawesi Tengah terletak di lembah Palu, bagian barat kota ini menghadap ke teluk Palu dengan kondisi kedalaman laut dangkal. Kota Palu termasuk sebagai daerah rawan gempa karena memiliki aktivitas tektonik tertinggi di Indonesia. Hal ini dikarena di kota Palu terdapat patahan kerak bumi (sesar) berdimensi cukup besar, dikenal dengan sesar Palukoro.

Berdasarkan kondisi seismisitas dan tektonik tersebut maka kawasan Kota Palu berpotensi terhadap bencana alam geologi terutama gempa bumi dengan intensitas dan frekuensi gempa yang cukup tinggi serta termasuk dalam tipe kerak dangkal (shallow crustal earthquakes). dan juga rawan terhadap tsunami.

\subsection{Teori Tsunami}

Pergerakan dari lempeng- lempeng tektonik tersebut berpotensi memicu terjadinya Tsunami. Kata Tsunami (dibaca tsoo-Nah-mee) sebenarnya berasal dari bahasa jepang, yang secara harafiah berarti gelombang besar di pelabuhan. Tsunami adalah serangkaian gelombang yang berjalan sangat jauh dengan periode waktu yang panjang, biasanya ditimbulkan oleh guncangan guncangan yang berhubungan dengan gempa bumi yang terjadi di bawah atau dekat dasar laut. Letusan - letusan gunung berapi, tanah longsor bawah laut, dan terbanan karang pantai.

\subsection{Teori Perairan Dangkal (Shallow Water Theory)}

Teori perairan dangkal adalah pendekatan yang digunakan dalam melakukan pemodelan tsunami secara numerik. Tiga persamaan matematika dasar (Ortiz dan Tanioka, 2005) yang digunakan adalah persamaan gerak (equation of motion), persamaan kontinuitas (equation of continuity) dan persamaan transport untuk stabilitas persamaan, yaitu:

a. Persamaan Kontinuitas :

$$
\frac{\partial \eta}{\partial t}+\frac{\partial[u(H)]}{\partial x}+\frac{\partial[v(H)]}{\partial y}+\frac{\partial[v(H)]}{\partial z}=0
$$


b. Persamaan Momentum :

arah sumbu $x$

$$
\frac{\partial u}{\partial t}+u \frac{\partial u}{\partial x}+v \frac{\partial u}{\partial y}+w \frac{\partial u}{\partial z}+\mathrm{g} \frac{\partial \eta}{\partial x}+\frac{\tau_{x}}{\rho}=0
$$

arah sumbu $y$

$$
\frac{\partial v}{\partial t}+u \frac{\partial v}{\partial x}+v \frac{\partial v}{\partial y}+w \frac{\partial v}{\partial z}+\mathrm{g} \frac{\partial \eta}{\partial y}+\frac{\tau_{y}}{\rho}=0
$$

- $\quad$ arah sumbu $z$

$$
\frac{\partial v}{\partial t}+u \frac{\partial w}{\partial x}+v \frac{\partial w}{\partial y}+w \frac{\partial w}{\partial z}+\mathrm{g} \frac{\partial \eta}{\partial z}+\frac{\tau_{z}}{\rho}=0
$$

c. Model Transport

$$
\frac{\partial \eta}{\partial t}+u \frac{\partial \eta}{\partial x}+v \frac{\partial \eta}{\partial y}+w \frac{\partial \eta}{\partial z}=0
$$

\subsection{Persamaan Differensial Parsial}

Persamaan differensial parsial linier orde dua yang seringkali dijumpai di lapangan biasanya dibagi menjadi tiga jenis yaitu eliptik, hiperbolik dan parabolik. Bentuk umum dari persamaan diferensial ini adalah sebagai berikut :

$$
\sum_{i=1}^{N} A_{i} \frac{\partial^{2} f}{\partial x_{i}^{2}}+\sum_{i=1}^{N} B_{i} \frac{\partial f}{\partial x_{i}}+C f+D=0
$$

\section{Hasil dan Pembahasan}

\subsection{Model Perambatan Gelombang Tsunami}

Model perambatan gelombang tsunami adalah sebagai berikut :

$2\left[\frac{\partial \eta}{\partial t}\right]+\frac{1}{\mathrm{~g}}\left[\frac{\partial M}{\partial t}\right]+5 \eta_{i-1, j+1}^{t}\left[\frac{\partial M}{\partial x}\right]+5 M_{i-1, j+1}^{t}\left[\frac{\partial \eta}{\partial x}\right]+5 \eta_{i+1, j-1}^{t}\left[\frac{\partial M}{\partial y}\right]$

$+5 M_{i+1, j-1}^{t}\left[\frac{\partial \eta}{\partial y}\right]+5 \eta_{i, j}^{t}\left[\frac{\partial M}{\partial z}\right]+5 M_{i, j}^{t}\left[\frac{\partial \eta}{\partial z}\right]=0$

\subsubsection{Mendefferensialkan Persamaan Perambatan Gelombang Tsunami}

Turunan kedua dari persamaan perambatan gelombang tsunami adalah sebagai berikut :

$$
\begin{aligned}
& \frac{1}{\mathrm{~g}} \frac{\partial^{2} M}{\partial t^{2}}+5\left[\eta_{i-1, j+1}^{t}\right] \frac{\partial^{2} M}{\partial x^{2}}+5\left[\eta_{i+1, j-1}^{t}\right] \frac{\partial^{2} M}{\partial y^{2}}+5\left[\eta_{i, j}^{t}\right] \frac{\partial^{2} M}{\partial z^{2}}+2 \frac{\partial^{2} \eta}{\partial t^{2}} \\
& +5\left[M_{i-1, j+1}^{k}\right] \frac{\partial^{2} \eta}{\partial x^{2}}+5\left[M_{i+1, j-1}^{k}\right] \frac{\partial^{2} \eta}{\partial y^{2}}+5\left[M_{i, j}^{k}\right] \frac{\partial^{2} \eta}{\partial z^{2}}=0
\end{aligned}
$$

4.1.2. Mengubah Koordinat $(x, y, z)$ ke dalam koordinat $(U, V, W)$

Sehingga persamaan perambatan gelombang tsunami dalam koordinat $(U, V, W)$ adalah sebagai berikut :

$\frac{1}{\mathrm{~g}}\left[\frac{\partial^{2} M}{\partial t^{2}}\right]+\frac{5}{J}\left[\frac{\partial^{2} M}{\partial U^{2}}\right]+\frac{5}{J}\left[\frac{\partial^{2} M}{\partial V^{2}}\right]+\left[\frac{\partial^{2} N}{\partial t^{2}}\right]+\frac{1}{J}\left[\frac{\partial^{2} N}{\partial U^{2}}\right]+\frac{1}{J}\left[\frac{\partial^{2} N}{\partial V^{2}}\right]=0$ 


\subsection{Metode Pemisahan Variabel}

$$
\begin{aligned}
& \frac{1}{\mathrm{~g}} \frac{J}{5}\left[\frac{\partial^{2} M}{\partial t^{2}}\right]+\left[\frac{\partial^{2} M}{\partial U^{2}}\right]+\left[\frac{\partial^{2} M}{\partial V^{2}}\right]=-\chi_{1} \\
& M(U, V, T)=A e^{-\chi_{1} u-\omega_{1} v+\left(\frac{1 J}{\mathrm{~g} 5}\right) \gamma_{1} t} \\
& J\left[\frac{\partial^{2} N}{\partial t^{2}}\right]+\left[\frac{\partial^{2} N}{\partial U^{2}}\right]+\left[\frac{\partial^{2} N}{\partial V^{2}}\right]=\chi_{2} \\
& N(U, V, T)=B e^{\chi_{2} u+\omega_{2} v-J \gamma_{2} T}
\end{aligned}
$$

Sehingga solusi persamaan perambatan gelombang tsunami dengan menggunakan metode pemisahan variabel adalah sebagai berikut :

$$
M(U, V, T) \cdot N(U, V, T)=\left((A B) e^{-(\chi) u^{2}-(\omega) v^{2}+\left(\frac{1 J^{2}}{5}\right)(\gamma) t^{2}}\right)
$$

\subsection{Solusi Sistem Persamaan Differensial}

Selanjutnya karena perambatan gelombang tsunami yang mengarah sejajar laut $(M)$ dan yang mengarah ke darat $(\mathrm{N})$ adalah sebuah sistem persamaan maka dari metode pemisahan variabel maka kita dapat mencari solusi sistem persamaan differensial perambatan gelombang Tsunami tersebut dengan menggunakan metode nilai eigen.

$$
-\left[\frac{\partial^{2} M}{\partial t^{2}}\right]=\frac{5 g}{J}\left[\frac{\partial^{2} M}{\partial U^{2}}\right]+\frac{5 g}{J}\left[\frac{\partial^{2} M}{\partial V^{2}}\right]=0
$$

dimana :

$$
\begin{aligned}
& U^{2}=-\frac{5 g}{J} \chi_{1} U \\
& V^{2}=-\frac{5 g}{J} \omega_{1} V
\end{aligned}
$$

dan,

$$
-J\left[\frac{\partial^{2} N}{\partial t^{2}}\right]=\left[\frac{\partial^{2} N}{\partial U^{2}}\right]+\left[\frac{\partial^{2} N}{\partial V^{2}}\right]
$$

dimana :

$$
\begin{aligned}
& U^{2}=\frac{1}{J} \chi_{2} U \\
& V^{2}=\frac{1}{J} \omega_{2} V \mathrm{~s}
\end{aligned}
$$

Sehingga dalam Sistem Persamaan Differensial adalah :

$$
\begin{aligned}
& M(t)=\frac{5 g}{J} \chi_{1} U+\frac{5 g}{J} \omega_{1} V \\
& N(t)=-\frac{1}{J} \chi_{2} U-\frac{1}{J} \omega_{2} V
\end{aligned}
$$

Sehingga persamaan karakteristik di atas adalah :

$$
\begin{aligned}
& Y_{1}=-\frac{1}{2} B \omega_{2}+\frac{1}{2} A \chi_{1}+\frac{1}{2} \sqrt{B^{2} \omega_{2}^{2}+2 A B \chi_{1} \omega_{2}+A^{2} \chi_{1}^{2}-4 A B \chi_{2} \omega_{1}} \\
& Y_{2}=-\frac{1}{2} B \omega_{2}+\frac{1}{2} A \chi_{1}-\frac{1}{2} \sqrt{B^{2} \omega_{2}^{2}+2 A B \chi_{1} \omega_{2}+A^{2} \chi_{1}^{2}-4 A B \chi_{2} \omega_{1}} \\
& M(t)=e^{Y_{1} t} ; N(t)=e^{\Upsilon_{2} t}
\end{aligned}
$$

Sehingga solusi yang memenuhi persamaan perambatan gelombang tsunami dengan menggunakan sistem persamaan differensial biasa adalah :

$$
M(t)=e^{\Upsilon_{1} t}
$$

Jadi, solusi sistem persamaan differensial dari persamaan perambatan gelombang tsunami adalah sebagai berikut $M(t)=e^{\Upsilon_{1} t}$. 


\subsection{Transformasi Koordinat Kartesian ke dalam Koordinat Bola}

Maka solusi persamaan perambatan gelombang akan dipenuhi oleh :

$$
M(U, V, t)=f^{\prime \prime}((U+V)-t)
$$

Hal ini disebabkan oleh :

$$
\begin{aligned}
& \left(\frac{1}{\mathrm{~g}} \frac{J}{5}\right)\left[\frac{\partial^{2} M}{\partial t^{2}}\right]=-f^{\prime \prime}((U+V)-t) ; \\
& {\left[\frac{\partial^{2} M}{\partial u^{2}}\right]+\left[\frac{\partial^{2} M}{\partial v^{2}}\right]=f^{\prime \prime}((U+V)-t) ;}
\end{aligned}
$$

Yang mana jumlah keduanya harus selalu nol, sehingga solusi fungsi yang memenuhi persamaan differensial parsial di atas adalah sebagai berikut :

$$
M(U, V, t)=e^{((U+V)-t)^{2}}
$$

Persamaan perambatan gelombang tsunami adalah sebagai berikut :

$$
\frac{1}{\mathrm{~g}} \frac{J}{5}\left[\frac{\partial^{2} M}{\partial t^{2}}\right]+2\left(\left[\frac{\partial^{2} M}{\partial U^{2}}\right]+\left[\frac{\partial^{2} M}{\partial V^{2}}\right]+\left[\frac{\partial^{2} M}{\partial Q^{2}}\right]\right)-\left(\left[\frac{\partial^{2} M}{\partial U^{2}}\right]+\left[\frac{\partial^{2} M}{\partial Q^{2}}\right]\right)-\left(\left[\frac{\partial^{2} M}{\partial U^{2}}\right]+\left[\frac{\partial^{2} M}{\partial Q^{2}}\right]\right) .
$$

Sehingga diperoleh persamaan perambatan gelombang tsunami dengan metode transformasi koordinat bola adalah sebagai berikut:

$$
\begin{aligned}
& \left(\frac{1}{\mathrm{~g}} \frac{J}{5}\right) \frac{\partial^{2} M}{\partial t^{2}}+\left[\frac{6}{A^{2}} \frac{\partial}{\partial A}\left(A^{2} \frac{\partial}{\partial A}\right)\right]+\frac{4}{A^{2} \sin ^{2} \vartheta_{2}} \frac{\partial}{\partial \vartheta_{1}}\left(\sin ^{2} \vartheta_{2} \frac{\partial}{\partial \vartheta_{1}}\right)+\left[\frac{4}{A^{2} \sin ^{2} \vartheta_{2}} \frac{\partial^{2}}{\partial \vartheta_{2}{ }^{2}}-\frac{1}{A^{2} \sin ^{2} \vartheta_{2}} \frac{\partial^{2}}{\partial \vartheta_{2}}\right]+ \\
& \frac{4}{A^{2} \cos ^{2} \vartheta_{1}} \frac{\partial}{\partial \vartheta_{2}}\left(\cos ^{2} \vartheta_{1} \frac{\partial}{\partial \vartheta_{2}}\right)+\left[\frac{4}{A^{2} \cos ^{2} \vartheta_{1}} \frac{\partial^{2}}{\partial \vartheta_{1}{ }^{2}}-\frac{1}{A^{2} \cos \vartheta_{1}} \frac{\partial}{\partial \vartheta_{1}}\left(\cos \vartheta_{1} \frac{\partial}{\partial \vartheta_{1}}\right)\right]=0
\end{aligned}
$$

atau,

$$
\left(\frac{1}{g} \frac{J}{5}\right) \frac{\partial^{2} M}{\partial t^{2}}+\nabla^{2} \bar{M}\left(A,\left(\vartheta_{1}, \vartheta_{2}\right)\right)
$$

\subsection{Metode Pemisahan Peubah}

\subsubsection{Peubah $t$}

Misalkan langkah selanjutnya adalah memisahkan peubah $t$ dari $\left(A, \vartheta_{1}, \vartheta_{2}\right)$ adalah sebagai berikut :

$$
\bar{M}\left(A,\left(\vartheta_{1}, \vartheta_{2}\right), t\right)=\phi\left(A,\left(\vartheta_{1}, \vartheta_{2}\right)\right) T(t)
$$

Subtitusi persamaan (31) ke dalam persamaan (32) , maka didapatkan :

$$
\frac{\partial^{2} T(t)}{\partial t^{2}} \phi\left(A,\left(\vartheta_{1}, \vartheta_{2}\right)\right)=-\left(\frac{1}{g} \frac{J}{5}\right) T(t) \nabla^{2} \phi\left(A,\left(\vartheta_{1}, \vartheta_{2}\right)\right)=-\psi
$$

Persamaan tersebut dipenuhi untuk suatu daerah tertentu apabila kedua sisi persamaan adalah sama dengan suatu konstanta tertentu, misalkan $\psi$, yang disebut sebagai konstanta pemisah diperoleh :

$$
\begin{aligned}
& \frac{\partial^{2} T(t) / \partial t^{2}}{\left(\frac{1}{\mathrm{~g} 5}\right) T(t)}=-\psi \\
& -\frac{\nabla^{2} \phi\left(A,\left(\vartheta_{1}, \vartheta_{2}\right)\right)}{\phi\left(A,\left(\vartheta_{1}, \vartheta_{2}\right)\right)}=-\psi \\
& \frac{\nabla^{2} \phi\left(A,\left(\vartheta_{1}, \vartheta_{2}\right)\right)}{\phi\left(A,\left(\vartheta_{1}, \vartheta_{2}\right)\right)}=\psi
\end{aligned}
$$

Solusi persamaan di atas dapat diselesaikan secara langsung dengan menggunakan metode persamaan differensial biasa. 


$$
\begin{aligned}
& \frac{\partial^{2} T(t)}{\partial t^{2}}=-\left(\frac{\psi}{\mathrm{g}} \frac{J}{5}\right) T(t) \\
& T^{\prime \prime}+\left(\frac{\psi}{\mathrm{g}} \frac{\mathrm{J}}{5}\right) T=0
\end{aligned}
$$

Persamaan karakteristiknya adalah

$$
T^{2}+\left(\frac{1}{\mathrm{~g}} \frac{\mathrm{J}}{5}\right) \psi=0
$$

Maka solusi umum dari persamaan (37) adalah :

$$
T(t)=C_{1} \cos \frac{1}{5} \sqrt{10 J \psi} t+C_{2} \sin \frac{1}{5} \sqrt{10 J \psi} t
$$

dimana $\psi$ adalah konstanta.

\subsubsection{Peubah $A$ dan $\left(\vartheta_{1}, \vartheta_{2}\right)$}

Pemisahan peubah yang dilakukan pada langkah awal terhadap Masalah Nilai Awal dan Batas memberikan :

$$
\begin{aligned}
& \nabla^{2} \phi\left(A,\left(\vartheta_{1}, \vartheta_{2}\right)\right)+\psi \phi\left(A,\left(\vartheta_{1}, \vartheta_{2}\right)\right)=0 \\
& M\left(0,\left(\vartheta_{1}, \vartheta_{2}\right)\right) ; M\left(A^{\prime},\left(\vartheta_{1}, \vartheta_{2}\right)\right)=0, \\
& M(A,(0,0)) ; M\left(A,\left(L_{x}, L_{y}\right)\right)=0, \\
& 0<A \leq A^{\prime} ; 0<\vartheta_{1} \leq L_{x} ; 0<\vartheta_{2} \leq L_{y} \\
& \frac{6}{\alpha} \frac{\partial}{\partial A}\left(A^{2} \frac{\partial \alpha}{\partial A}\right)+\left[\frac{1}{\beta} \frac{3}{\sin ^{2} \vartheta_{2}} \frac{\partial^{2} \beta}{\partial \vartheta_{2}^{2}}\right]+\frac{4}{\beta} \frac{1}{\sin ^{2} \vartheta_{2}} \frac{\partial}{\partial \vartheta_{1}}\left(\sin ^{2} \vartheta_{2} \frac{\partial \beta}{\partial \vartheta_{1}}\right)+\left[\frac{1}{\beta} \frac{3}{\cos ^{2} \vartheta_{1}} \frac{\partial^{2} \beta}{\partial \vartheta_{1}^{2}}\right] \\
& +\frac{4}{\beta} \frac{1}{\cos ^{2} \vartheta_{1}} \frac{\partial}{\partial \vartheta_{2}}\left(\cos ^{2} \vartheta_{1} \frac{\partial \beta}{\partial \vartheta_{2}}\right)+\psi A^{2}=0
\end{aligned}
$$

adapun penjabaran dua persamaan tersebut adalah sebagai berikut :

\section{a. Persamaan Radial}

$$
\frac{6}{\alpha} \frac{\partial}{\partial A}\left(A^{2} \frac{\partial \alpha}{\partial A}\right)+\psi A^{2}=2 \lambda
$$

dimana koordinat $\beta\left(\vartheta_{1}, \vartheta_{2}\right)$ menunjukkan perambatan gelombang tsunami pada permukaan air yang menjalar secara (horizontal) baik sejajar pantai dan mendekati daratan, sementara perambatan gelombang tsunami tidak mengarah secara vertical maka persamaan radial ditiadakan.

\section{b. Persamaan Angular}

$$
\begin{aligned}
& {\left[\left[\frac{1}{\beta} \frac{3}{\sin ^{2} \vartheta_{2}} \frac{\partial^{2} \beta}{\partial \vartheta_{2}^{2}}\right]+\frac{4}{\beta} \frac{1}{\sin ^{2} \vartheta_{2}} \frac{\partial}{\partial \vartheta_{1}}\left(\sin ^{2} \vartheta_{2} \frac{\partial \beta}{\partial \vartheta_{1}}\right)\right]+} \\
& {\left[\left[\frac{1}{\beta} \frac{3}{\cos ^{2} \vartheta_{1}} \frac{\partial^{2} \beta}{\partial \vartheta_{1}^{2}}\right]+\frac{4}{\beta} \frac{1}{\cos ^{2} \vartheta_{1}} \frac{\partial}{\partial \vartheta_{2}}\left(\cos ^{2} \vartheta_{1} \frac{\partial \beta}{\partial \vartheta_{2}}\right)\right]=-2 \lambda}
\end{aligned}
$$

Pisahkan antara sudut sinus yang menyatakan perambatan sejajar pantai dan sudut cosinus yang menyatakan perambatan mengarah ke darat maka :

b.1. Arah sejajar pantai

$$
\begin{aligned}
& {\left[\left[\frac{1}{\beta} \frac{3}{\sin ^{2} \vartheta_{2}} \frac{\partial^{2} \beta}{\partial \vartheta_{2}^{2}}\right]+\frac{4}{\beta} \frac{1}{\sin ^{2} \vartheta_{2}} \frac{\partial}{\partial \vartheta_{1}}\left(\sin ^{2} \vartheta_{2} \frac{\partial \beta}{\partial \vartheta_{1}}\right)\right]=-\lambda} \\
& \beta\left(\vartheta_{1}, \vartheta_{2}\right) \equiv \beta_{x}\left(\vartheta_{1}, \vartheta_{2}\right) \\
& \beta_{x}\left(\vartheta_{1}, \vartheta_{2}\right)=\Theta\left(\vartheta_{1}\right) \Phi\left(\vartheta_{2}\right)
\end{aligned}
$$


$\frac{1}{\beta}\left[\frac{3}{\sin ^{2} \vartheta_{2}} \frac{\partial}{\partial \vartheta_{2}}\left(\sin ^{2} \vartheta_{2} \frac{\partial \beta}{\partial \vartheta_{2}}\right)+\frac{4}{\sin ^{2} \vartheta_{2}} \frac{\partial^{2} \beta}{\partial \vartheta_{1}^{2}}\right]=-\lambda \beta$

$\left[\frac{3 \Theta}{\sin ^{2} \vartheta_{2}} \frac{\partial}{\partial \vartheta_{2}}\left(\sin ^{2} \vartheta_{2} \frac{\partial \Phi}{\partial \vartheta_{2}}\right)+\frac{4 \Phi}{\sin ^{2} \vartheta_{2}} \frac{\partial^{2} \Theta}{\partial \vartheta_{1}^{2}}\right]+3 \Theta \Phi \lambda=0$

Mengalikan persamaan dengan $\frac{\sin ^{2} \vartheta_{2}}{\Theta \Phi}$ maka didapatkan :

$\left[\frac{3 \sin \vartheta_{2}}{\Phi} \frac{d}{d \vartheta_{2}}\left(\sin \vartheta_{2} \frac{d \Phi}{d \vartheta_{2}}\right)+\frac{4}{\Theta} \frac{d^{2} \Theta}{d \vartheta_{1}^{2}}\right]+3 \lambda \sin ^{2} \vartheta_{2}=0$

$\left[\frac{3 \sin \vartheta_{2}}{\Phi} \frac{d}{d \vartheta_{2}}\left(\sin \vartheta_{2} \frac{d \Phi}{d \vartheta_{2}}\right)+3 \lambda \sin ^{2} \vartheta_{2}\right]+\frac{4}{\Phi} \frac{d^{2} \Phi}{d \vartheta_{1}^{2}}=0$

Dalam persamaan (45) di atas dapat dibagi atas dua persamaan yaitu persamaan polar dan azimut adalah sebagai berikut :

- Persamaan Polar

$\left[\frac{3 \sin \vartheta_{2}}{\Phi} \frac{d}{d \vartheta_{2}}\left(\sin \vartheta_{2} \frac{d \Phi}{d \vartheta_{2}}\right)+3 \lambda \sin ^{2} \vartheta_{2}\right]=\xi$

Karena persamaan (43) hanya sejajar pantai, maka persamaan (46) ditiadakan.

Persamaan Azimut

Misalkan :

$\frac{4}{\Theta} \frac{d^{2} \Theta}{d \vartheta_{1}^{2}}=-\xi$

$4 \frac{d^{2} \Theta}{d \vartheta_{1}^{2}}+\xi \Theta=0$

Untuk menyelesaikan persamaan (47) maka di bawah ke bentuk persamaan diferensial biasa menjadi $4 r^{2}+\xi=0$. Persamaan karakteristik (47) jika akar $r_{1}$ dan $r_{2}$ dicari, akan didapatkan :

$r_{12}=\frac{-b \pm \sqrt{b^{2}-4 a c}}{2 a}$

$=\frac{0 \pm \sqrt{0-4(4) \cdot(\xi)}}{2(4)}$

$=\frac{ \pm \sqrt{0-16(\xi)}}{8}$

$= \pm \frac{1}{2} \sqrt{-\xi}$

Jadi, solusi persamaan $4 r^{2}+\xi=0$ adalah $\Theta\left(\vartheta_{1}\right)=C_{2} \sin \left(\frac{\eta_{i-1, j+1}^{t}}{L_{X}}\right) \vartheta_{1}$

b.2. Arah menuju darat

$\left[\left[\frac{1}{\beta} \frac{3}{\cos ^{2} \vartheta_{1}} \frac{\partial^{2} \beta}{\partial \vartheta_{1}^{2}}\right]+\frac{4}{B} \frac{1}{\cos ^{2} \vartheta_{1}} \frac{\partial}{\partial \vartheta_{2}}\left(\cos ^{2} \vartheta_{1} \frac{\partial \beta}{\partial \vartheta_{2}}\right)\right]=-\lambda$

$M_{y}\left(A, \vartheta_{1}, \vartheta_{2}\right) \equiv \alpha(A) \beta_{y}\left(\vartheta_{1}, \vartheta_{2}\right)$

$\beta_{y}\left(\vartheta_{1}, \vartheta_{2}\right)=\Theta\left(\vartheta_{1}\right) \Phi\left(\vartheta_{2}\right)$

$\frac{1}{B}\left[\frac{3}{\cos ^{2} \vartheta_{1}} \frac{\partial^{2} \beta}{\partial \vartheta_{1}^{2}}\left(\cos ^{2} \vartheta_{1} \frac{\partial \beta}{\partial \vartheta_{1}}\right)+\frac{4}{\cos ^{2} \vartheta_{1}} \frac{\partial^{2} \beta}{\partial \vartheta_{2}^{2}}\right]=-\lambda$

$\left[\frac{3 \Phi}{\cos ^{2} \vartheta_{1}} \frac{\partial}{\partial \vartheta_{1}}\left(\cos ^{2} \vartheta_{1} \frac{\partial \Theta}{\partial \vartheta_{1}}\right)+\frac{4 \Theta}{\cos ^{2} \vartheta_{1}} \frac{\partial^{2} \Phi}{\partial \vartheta_{2}^{2}}\right]+\Theta \Phi \lambda=0$

Mengalikan persamaan dengan $\frac{\cos ^{2} \vartheta_{1}}{\Theta \Phi}$ maka didapatkan :

$\left[\frac{3 \cos \vartheta_{1}}{\Theta} \frac{d}{d \vartheta_{1}}\left(\cos \vartheta_{1} \frac{d \Theta}{d \vartheta_{1}}\right)+\frac{4}{\Phi} \frac{d^{2} \Phi}{d \vartheta_{2}^{2}}\right]+\lambda \cos ^{2} \vartheta_{1}=0$ 
$\left[\frac{3 \cos \vartheta_{1}}{\Theta} \frac{d}{d \vartheta_{1}}\left(\cos \vartheta_{1} \frac{d \Theta}{d \vartheta_{1}}\right)+\lambda \cos ^{2} \vartheta_{1}\right]+\frac{4}{\Phi} \frac{d^{2} \Phi}{d \vartheta_{2}^{2}}=0$

Dalam persamaan (39) di atas dapat dibagi atas dua persamaan yaitu persamaan polar dan azimut adalah sebagai berikut :

Persamaan Polar :

$\left[\frac{3 \cos \vartheta_{1}}{\Theta} \frac{d}{d \vartheta_{1}}\left(\cos \vartheta_{1} \frac{d \Theta}{d \vartheta_{1}}\right)+2 \lambda \cos ^{2} \vartheta_{1}\right]=\zeta$

Karena persamaan (49) menuju ke darat, maka persamaan (51) ditiadakan.

Persamaan Azimut :

$\frac{4}{\Phi} \frac{d^{2} \Phi}{d \vartheta_{2}^{2}}=-\zeta$

$\frac{4}{\Phi} \frac{d^{2} \Phi}{d \vartheta_{2}^{2}}+\zeta \Phi=0$

Untuk menyelesaikan persamaan (52) maka di bawah ke bentuk persamaan diferensial biasa menjadi $4 q^{2}+\zeta=0$. Persamaan karakteristik (52) jika akar $q_{1}$ dan $q_{2}$ dicari, akan didapatkan :

$q_{12}=\frac{-b \pm \sqrt{b^{2}-4 a c}}{2 a}$

$=\frac{0 \pm \sqrt{0-4(4) \cdot(\zeta)}}{2(4)}$

$=\frac{ \pm \sqrt{0-16(\zeta)}}{8}$

$= \pm \frac{1}{2} \sqrt{-\zeta}$

Jadi, solusi persamaan $4 q^{2}+\zeta=0$ adalah $\Phi\left(\vartheta_{2}\right)=C_{1} \cos \left(\frac{\eta_{i+1, j-1}^{t}}{L_{y}}\right) \vartheta_{2}$

Dari penyelesaian persamaan perambatan gelombang dengan metode pemisahan variabel , solusi sistem persamaan differensial biasa dan metode transformasi koordinat kartesian ke koordinat bola dengan menggunakan metode pemisahan peubah dan persamaan differensial biasa diperoleh solusi umum profil dari Persamaan Perambatan Gelombang tiga dimensi adalah sebagai berikut: $\bar{M}(U, V, t)=[M(U, V, T) \cdot N(U, V, T)]+M(T)+M(U, V, T)$ $\bar{M}(U, V, t)=\left((E) e^{-(\chi) x^{2}-(\omega) y^{2}+\left(\frac{1 J^{2}}{\mathrm{~g} 5}\right)(\gamma) t^{2}}\right)+$ $e^{\Upsilon_{1} t\left(2 C_{2} \cos \frac{1}{2}\left[\frac{1}{5} \sqrt{10 J \psi} t+\left(\frac{\eta_{i-1, j+1}^{t}}{L_{X}}\right) u\right] \cdot C_{2} \sin \frac{1}{2}\left[\frac{1}{5} \sqrt{10 J \psi} t-\left(\frac{\eta_{i-1, j+1}^{t}}{L_{X}}\right) u\right]-2 C_{1} \sin \frac{1}{2}\left[\frac{1}{5} \sqrt{10 J \psi} t+\left(\frac{\eta_{i+1, j-1}^{t}}{L_{y}}\right) v\right] \cdot C_{1} \sin \frac{1}{2}\left[\frac{1}{5} \sqrt{10 J \psi t} t-\left(\frac{\eta_{i+1, j-1}^{t}}{L_{y}}\right) v\right]\right)^{2}}$

Jadi, persamaan (54) adalah profil persamaan perambatan gelombang tsunami. 


\subsection{Simulasi}

4.5.1. Gelombang Tsunami pertama kali muncul di permukaan Laut $t=0$.

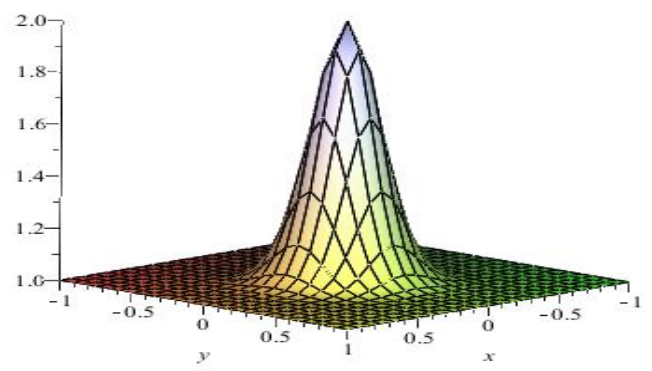

Gambar 1 : Gelombang Tsunami pertama kali muncul di permukaan Laut $t=1.166666667$

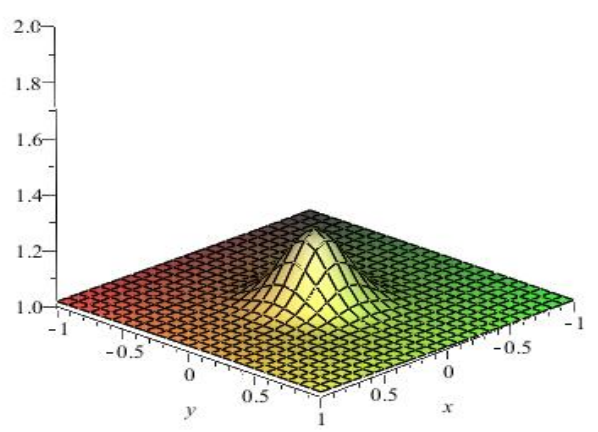

Gambar 2 : Gelombang Tsunami mulai merambat ke arah perambatannya $t=3.208333333$

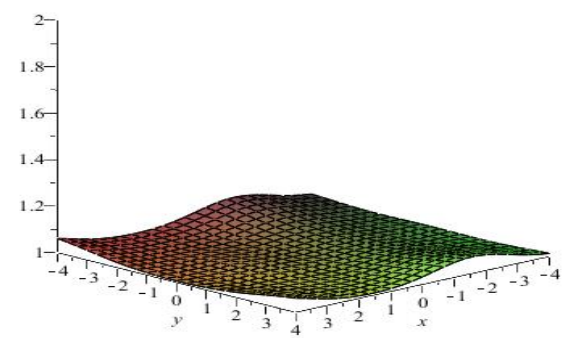

Gambar 3 : Gelombang Tsunami menjalar ke arah rambatannya dengan ketinggian elevasi yang masih sejajar permukaan laut. 


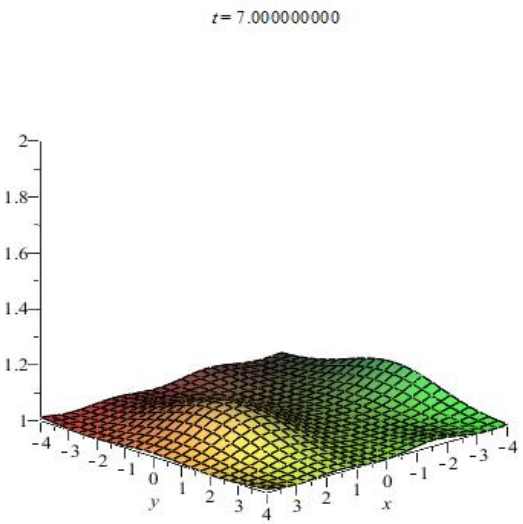

Gambar 4: Gelombang Tsunami menjalar ke arah rambatannya dengan ketinggian elevasi yang mulai meningkat.

4.5.2. Perambatan Gelombang Tsunami di permukaan laut

$t=15.00000000$

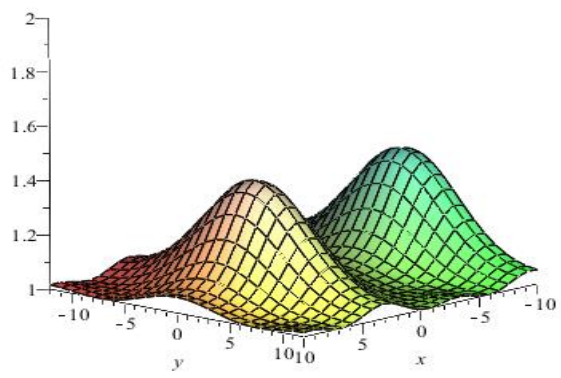

Gambar 5 : Kecepatan gelombang dan ketinggian elevasi gelombang tsunami meningkat. 


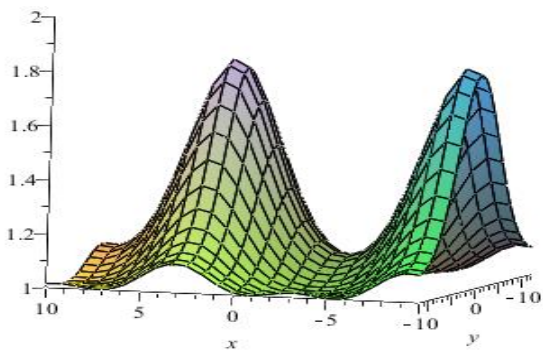

Gambar 6 : Ketinggian elevasi gelom-bang tsunami makin meningkat menuju daratan.

\subsubsection{Perambatan Gelombang Tsunami pada saat menuju ke daratan}

\section{$t=161.2500000$}

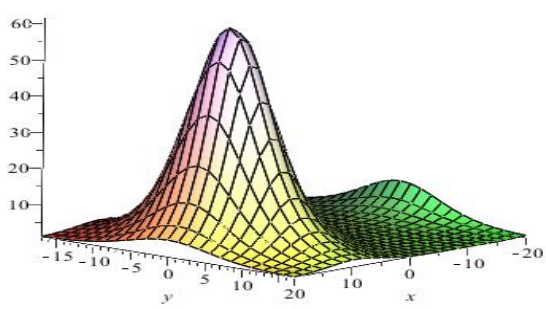

Gambar 7: Kecepatan gelombang dan ketinggian elevasi gelombang tsunami meningkat.

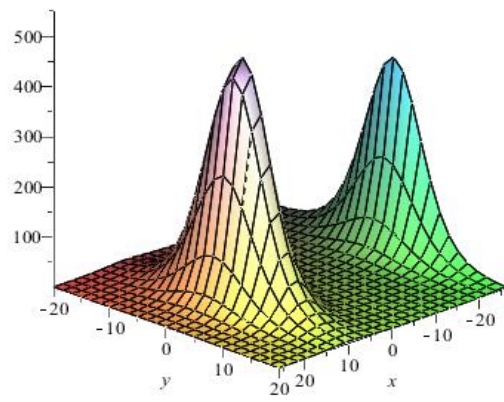

Gambar 8 : Ketinggian elevasi gelom-bang tsunami makin meningkat menuju daratan. 
4.5.4. Perambatan Gelombang Tsunami mendekati daratan

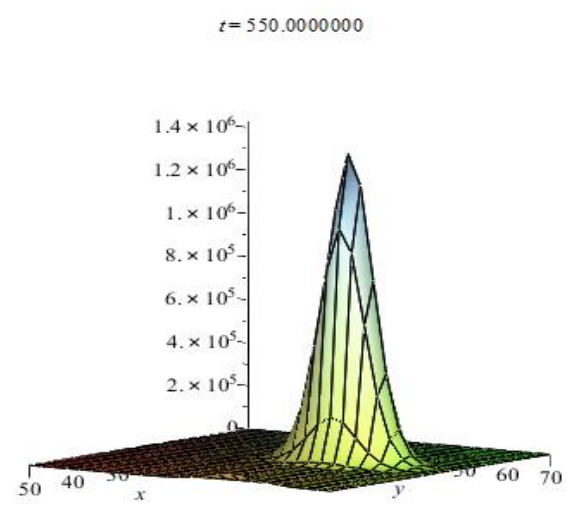

Gambar 9 : Ketinggian elevasi gelombang tsunami lebih meningkat meuju daratan.

$t=705.0000000$

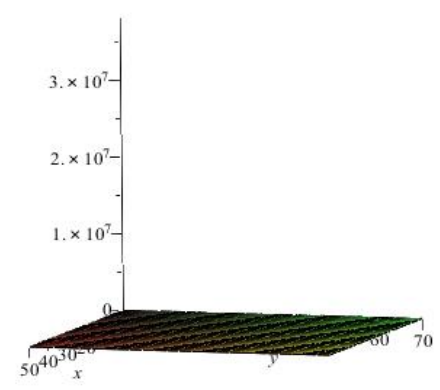

Gambar 10 : Kecepatan dan ketinggian elevasi pada saat Gelombang Tsunami telah redah.

\section{PENUTUP}

\subsection{Kesimpulan}

1. Persamaan gelombang Tsunami 3 Dimensi dengan metode transformasi koordinat bola adalah sebagai berikut :

$$
\begin{aligned}
\left(\frac{1}{\mathrm{~g}} \frac{\mathrm{J}}{5}\right) \frac{\partial^{2} M}{\partial t^{2}}+\left[\frac{6}{A^{2}}\right. & \frac{\partial}{\partial A} \\
& \left.\left(A^{2} \frac{\partial}{\partial A}\right)\right]+\frac{4}{A^{2} \sin ^{2} \vartheta_{2}} \frac{\partial}{\partial \vartheta_{1}}\left(\sin ^{2} \vartheta_{2} \frac{\partial}{\partial \vartheta_{1}}\right)+\left[\frac{4}{A^{2} \sin ^{2} \vartheta_{2}} \frac{\partial^{2}}{\partial \vartheta_{2}{ }^{2}}-\frac{1}{A^{2} \sin ^{2} \vartheta_{2}} \frac{\partial^{2}}{\partial \vartheta_{2}}\right] \\
& +\frac{4}{A^{2} \cos ^{2} \vartheta_{1}} \frac{\partial}{\partial \vartheta_{2}}\left(\cos ^{2} \vartheta_{1} \frac{\partial}{\partial \vartheta_{2}}\right)+\left[\frac{4}{A^{2} \cos ^{2} \vartheta_{1}} \frac{\partial^{2}}{\partial \vartheta_{1}{ }^{2}}-\frac{1}{A^{2} \cos \vartheta_{1}} \frac{\partial}{\partial \vartheta_{1}}\left(\cos \vartheta_{1} \frac{\partial}{\partial \vartheta_{1}}\right)\right] \\
& =0
\end{aligned}
$$

dimana :

A

: Konstanta 
$\operatorname{Sin} \vartheta_{1}, \operatorname{Cos} \vartheta_{1} \quad$ : Sudut dalam arah $x$

$\operatorname{Sin} \vartheta_{2}, \operatorname{Cos} \vartheta_{2} \quad$ : Sudut dalam arah $y$

$t$

: Waktu (detik)

$u$ dan $v$ : Kecepatan partikel air arah $x$ dan $y\left(m / \operatorname{detik}^{2}\right)$

$\partial$ : Turunan parsial

2. Solusi dari perambatan gelombang Tsunami di perairan teluk palu adalah sebagai berikut :

$$
\begin{aligned}
& \bar{M}(U, V, t)=\left((E) e^{-(\chi) x^{2}-(\omega) y^{2}+\left(\frac{1 J^{2}}{\mathrm{~g} 5}\right)(\gamma) t^{2}}\right)+
\end{aligned}
$$

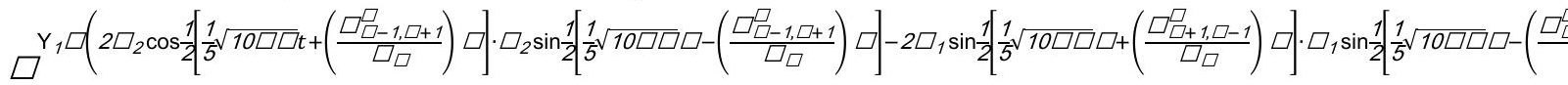

3. Gelombang mencapai bibir pantai pada saat 705 detik atau 11,75 menit dengan kecepatan yang sejajar laut $45 \mathrm{~km} /$ menit dan mengarah ke darat $68 \mathrm{~km} /$ menit. Itu berarti perambatan gelombang tsunami di perairan teluk palu cukup tinggi, untuk memperkecil perambatan gelombang tsunami di perairan teluk palu dan dampak atau korban dari gelombang tsunami perlu adanya budidaya hutan mangrove dan tempat mitigasi bencana yang terjangkau khususnya bagi masyarakat di wilayah Kota Palu dan sekitarnya .

\subsection{Saran}

Bagi Mahasiswa yang tertarik untuk mempelajari tentang analisis numerik dapat mencari nilai perambatan gelombang tsunami di setiap waktu dengan menggunakan metode beda hingga yang diterapkan.

\section{Daftar Pustaka}

[1]. Wagener, A. 1915. The Origin of Continents an Oceans. Jerman.

[2]. Ortiz, M. dan Tanioka, Y. 2005. Catatan Kursus Pemrograman Pemodelan Tsunami. Quezon City. Filipina. 